University of Massachusetts Amherst ScholarWorks@UMass Amherst

Masters Theses 1911 - February 2014

January 2008

\title{
Emotion and Executive Functioning: The Effect of Normal Mood States on Fluency Tasks
}

Janessa O. Carvalho

University of Massachusetts Amherst

Follow this and additional works at: https://scholarworks.umass.edu/theses

Carvalho, Janessa O., "Emotion and Executive Functioning: The Effect of Normal Mood States on Fluency Tasks" (2008). Masters Theses 1911 - February 2014. 121.

Retrieved from https://scholarworks.umass.edu/theses/121

This thesis is brought to you for free and open access by ScholarWorks@UMass Amherst. It has been accepted for inclusion in Masters Theses 1911 -

February 2014 by an authorized administrator of ScholarWorks@UMass Amherst. For more information, please contact

scholarworks@library.umass.edu. 
EMOTION AND EXECUTIVE FUNCTIONING: THE EFFECT OF NORMAL MOOD STATES ON FLUENCY TASKS

A Thesis Presented

by

JANESSA O. CARVALHO

Submitted to the Graduate School of the University of Massachusetts Amherst in partial fulfillment of the requirements for the degree of

\section{MASTER OF SCIENCE}

May 2008

Clinical Psychology 
EMOTION AND EXECUTIVE FUNCTIONING: THE EFFECT OF NORMAL MOOD STATES ON FLUENCY TASKS

A Thesis Presented

By

Janessa O. Carvalho

Approved as to style and content by:

Rebecca E. Ready, Chair

Susan Krauss Whitbourne, Member

Tamara Rahhal, Member

Melinda Novak, Department Head

Department of Psychology 


\begin{abstract}
EMOTION AND EXECUTIVE FUNCTIONING: THE EFFECT OF NORMAL MOOD STATES ON FLUENCY TASKS
\end{abstract}

MAY 2008

\title{
JANESSA O. CARVALHO, B.S., BRIDGEWATER STATE COLLEGE M.S., UNIVERSITY OF MASSACHUSETTS AMHERST
}

Directed by: Professor Rebecca Ready, Ph.D.

EEG activation studies suggest cerebral lateralization of emotions with greater left than right prefrontal activation during positive mood states and greater right than left prefrontal activation during negative mood states (Davidson et al., 1990). Cerebral lateralization is also observed in cognitive tasks, with verbal fluency associated with left frontal activation and design fluency associated with right frontal activation (Baldo et al., 2001). Further, there are lateralized associations between emotion and cognition; that is, verbal fluency is positively associated with induced positive mood, whereas design fluency is positively associated with induced negative mood (Bartolic et al., 1999). The current study expected naturally occurring mood states to be differentially associated with performance on executive function fluency tasks, and based on previous findings (Cabeza, 2002), that age would moderate the association between emotion and fluency. Results suggest a trend for a positive association between positive affect (PA) and verbal fluency. Age did not moderate associations between emotion and cognitive tasks, although greater interdependence between cognitive and emotion variables in older relative to middle-aged adults suggests decreased lateralization in older adults; however differences in interdependence between older and younger adults were negligible. These results suggest that PA may 
positively influence some areas of cognition, although age may not moderate these results. Sample and measurement limitations may have contributed to this finding. 


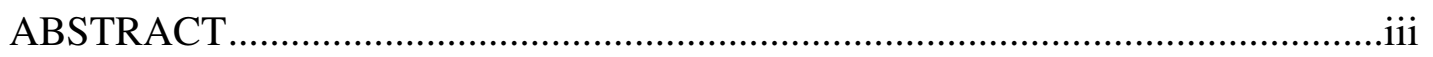

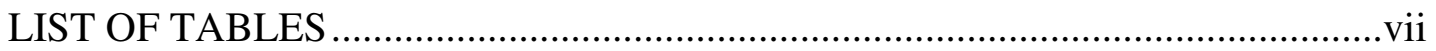

\section{CHAPTER}

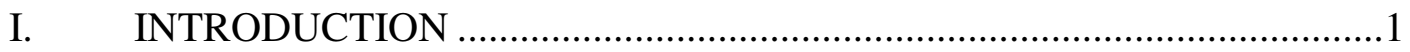

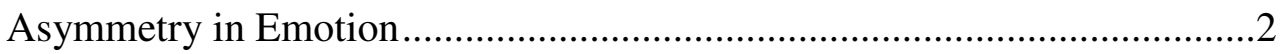

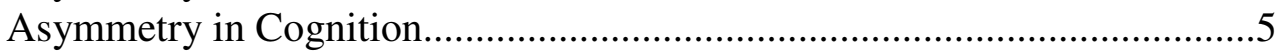

Emotion and Cognition ......................................................................

Cognitive and Emotion Changes in Aging …........................................ 9

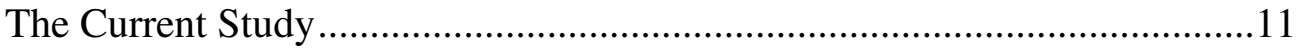

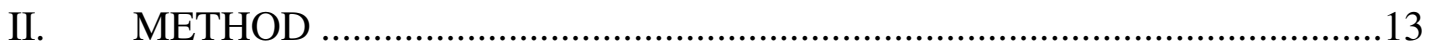

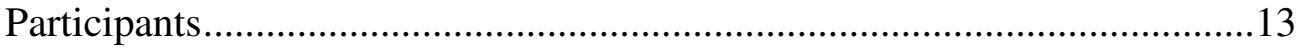

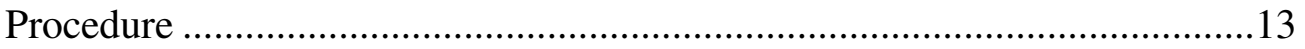

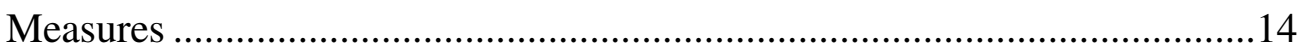

Emotion Judgment Task .............................................................14

Subtests from the Delis-Kaplan Executive Functioning System .......15

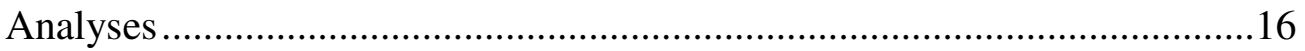

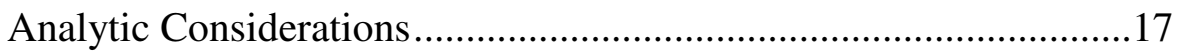

Analyses to Test Hypothesis One ....................................................18

Analyses to Test Hypothesis Two...................................................19

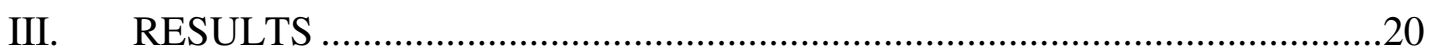

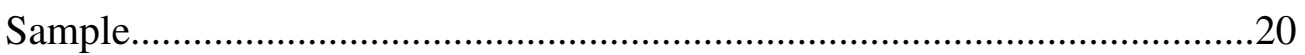

Internal Consistency Reliability of Affect Measures...................................20

Age Group Differences on Executive Function Tasks and Emotional

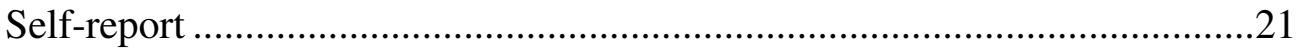

Correlations between Affect Scores...................................................21

Correlations between Outcome and Predictor Variables ..............................22

Linear Regressions: Analyses to Test Associations between

Affect and Fluency Performance.

Moderated Multiple Regression Analyses: Analyses to Test Age as a

Moderator of Associations between Affect and Fluency

Performance.

Age, Verbal Fluency, and their Interaction on PA.................24

Age, Design Fluency, and their Interaction on PA .................25

Age, Verbal Fluency, and their Interaction on NA ................26 


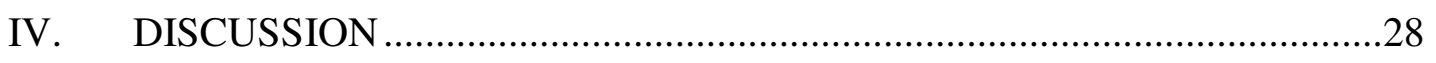

Associations between Verbal Fluency and PA ........................................28

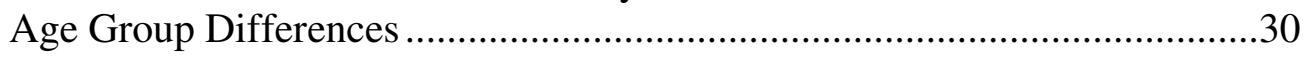

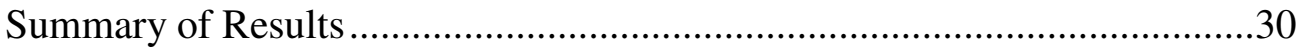

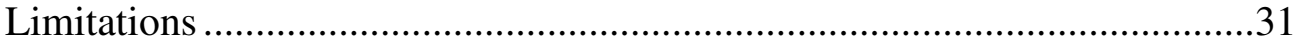

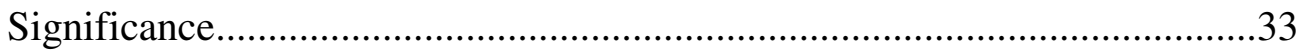

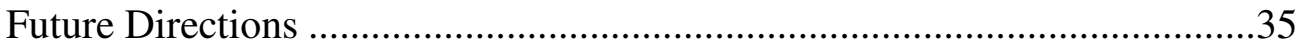

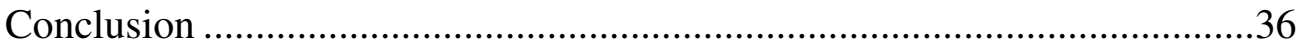

APPENDIX: LIST OF TERMS FROM THE EMOTION JUDGMENT TASK ......43

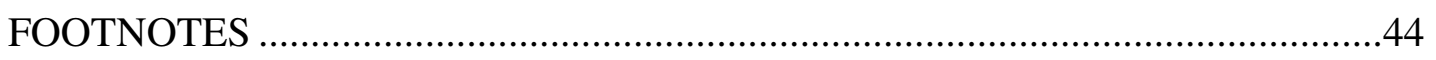

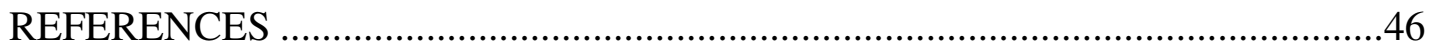




\section{LIST OF TABLES}

Table

1. Descriptive Statistics for Younger, Middle-Aged, and Older

Adults for Demographic, Fluency, and Affect Scores

2. Internal Consistency Reliabilities of Emotion Judgment Task Measures

3. Correlations between Fluency and Affect Scores for Younger, Middle-Aged, And Older Adults

4. Effects of Executive Functions on Emotion Scores: Linear Regressions

5. Effect of Age, Executive Functions, and their Interaction on Emotion Scores:

Moderated Hierarchical Regressions .40 


\section{CHAPTER I}

\section{INTRODUCTION}

Interest in the interface between emotion and cognition has grown considerably in recent years (Blanchard-Fields, 2005; Yiend, 2004). One useful approach to determine the potential interplay between emotion and cognition is to study lateralized functions because the left and right hemispheres of the brain appear to subserve different emotional and cognitive functions (Bush, Luu, \& Posner, 2000). For example, cerebral asymmetry has been observed during different emotion states, with greater relative left than right hemisphere activation during approach-related, or positive mood states, and greater relative right than left hemisphere activation during withdrawal, or negative mood states (Davidson, Chapman, Chapman, \& Henriques, 1990).

Cerebral lateralization also is observed during executive functioning tasks, such as visual and figural fluency (Baldo, Shimamura, Delis, Kramer, \& Kaplan, 2001). Verbal fluency is a task mediated by the left hemisphere, specifically left frontal circuitry (Butler, Rorsman, Hill, \& Tuma, 1993), whereas figural fluency is mediated by right frontal circuitry (Jones-Gotman, 1991). Together, lateralization in emotion and executive functions suggest that there might be functional links between the two constructs, such that, for example, differences in emotions might differentially affect cognition (Bartolic, Basso, Schefft, Glauser, \& Titanic-Schefft, 1999; Greene \& Noice, 1988; Herrington et al., 2005). In fact, past research has found that induced positive mood is positively associated with verbal fluency, whereas induced negative mood is positively associated with figural fluency performance (Bartolic et al., 1999).

The current study seeks to build on this previous research by determining associations between naturally occurring, everyday mood states, and performance on fluency tasks, which 
assess one aspect of executive functioning. This study also seeks to investigate whether age differences occur in cerebral lateralization. That is, although there is strong support for cerebral lateralization in younger adults, research suggests that there may be lesser lateralization in older adults, at least for cognitive tasks (Cabeza et al., 1997; Cabeza, 2001, 2002). That is, the Hemispheric Asymmetry Reduction in Old Adults (HAROLD) theory posits that older adults exhibit less cerebral lateralization and greater bilateral activation during cognitive tasks (Cabeza, 2002).

Thus, the current study seeks to provide a better understanding of associations between positive and negative mood states and verbal and figural fluency performance, which are lateralized executive functions. Furthermore, the study will investigate whether these associations are evident in adults of all ages, or whether older adults exhibit weakened lateralization effects. Ultimately, research along these lines will determine if executive functioning, measured by performance on fluency tasks, may be enhanced or degraded by different mood states. The construct of executive functions is an important one that influences most areas of cognition (Lezak, Howieson, \& Loring, 2004), and thus, an increased awareness of factors influencing executive functioning is crucial. Evidence supporting associations between fluency performance and emotion is presented in the following sections.

\section{$\underline{\text { Asymmetry and Emotion }}$}

Cerebral lateralization in emotion has been widely investigated over the past three decades with general agreement across studies (Davidson, 2004). Specifically, results of electroencephalographic (EEG) studies of hemispheric asymmetry and emotion have consistently found greater cerebral activation in the left hemisphere relative to activation in the right during positive mood states (Allen \& Kline, 2004; Cacioppo, 2004; Davidson, et al., 1990; Davidson, 
Eckman, Saron, Senulis, \& Friesen, 1990; Davidson, 1998; Davidson, 2001a; Davidson, 2004; Heller, 1993; Heller, Nitschke, \& Lindsay, 1997; Heller \& Nitschke, 1998; Heller, Nitschke, \& Miller, 1998; Herrington et al., 2005; Jackson et al., 2003; Lee et al., 2004). Alternatively, findings have shown relative greater activation in the right hemisphere compared to activation in the left during negative mood states (Davidson et al., 1990; Heller, 1998; Heller \& Nitschke, 1998; Lee et al., 2004). For example, in one study, individuals were presented with either positive or negative film clips; the positive condition elicited greater positive emotion and relatively greater left than right frontal hemisphere activity, whereas the negative condition elicited greater negative emotion and relatively greater right than left frontal hemisphere activation (Davidson et al., 1990). Furthermore, bilateral decreases in prefrontal cortical activity are associated with blunted positive and negative emotional experiences (Davidson, 1998).

Lateralized activity in the frontal lobes also is differentially associated with trait affect. That is, there is temporal stability of frontal asymmetry in emotion; results of anterior EEG asymmetry in emotion measures during two time frames (three weeks apart) suggest good testretest stability and excellent internal consistency reliability over time (Tomarken, Davidson, Wheller, \& Kinney, 1992). Furthermore, frontal asymmetries also have been found with traits such as sociability, which is associated with left frontal activation, and aggression, which is associated with right frontal activation (Harmon-Jones \& Allen, 1998; Schmidt, 1999). Research also suggests that trait affect remains stable over time as resting anterior asymmetry tends to be associated with a style of emotional reaction that persists throughout the lifespan (Kline, Blackhart, Woodward, Williams, \& Schwartz, 2000). Similarities between trait and state emotion asymmetries may occur because much of the neural circuitry involved in emotion remains relatively stable over time (Davidson, 2001b). 
One theory about the role of anterior cerebral processes in emotion suggests differential activity within each hemisphere. Davidson (1998) discusses two systems modulating PA and NA. These are approach-related emotion and withdrawal-related emotion, respectively. Approach-related emotion, or PA, subserved by the left cerebral hemisphere, is experienced as individuals move closer to a goal (Davidson, 1998) and when an individual anticipates receiving an award (Davidson, 2004). Withdrawal-related emotion, or NA, subserved by the right hemisphere, involves aversion such as disgust or fear (Davidson, 2004). Support for this model comes, in part, from Davidson and colleagues (1990), who found relative greater right frontal activation after viewing photographs to elicit "disgust" and relatively greater left activation during presentation of "happy" stimuli (Davidson et al., 1990).

Sutton and Davidson (1997) similarly found that young adults with relative greater left frontal activation endorsed greater seeking behavior in response to incentives, whereas individuals with greater right frontal activation endorsed more inhibitory behavior and attention to aversive stimuli, on the Behavior Approach and Inhibition Systems (BAS/BIS). That is, individuals who endorsed stronger responses to more positive or incentive bearing situations (i.e., greater approach-related behavior) demonstrated greater left than right frontal activation, whereas individuals who endorsed stronger responses to more negative or threat oriented situations, such as withdrawal-related emotions, demonstrated greater right than left frontal activation (Sutton \& Davidson, 1997). These results also support frontal alpha asymmetry in relation to personality traits, as discussed above, because those who endorsed stronger incentiverelated behavior were more extraverted, while those endorsing stronger threat-related behavior were more neurotic (Sutton \& Davidson, 1997). Overall, these findings suggest that left prefrontal systems are responsible for modulating approach-related activity whereas right 
prefrontal systems modulate withdrawal-related emotional experiences, and provide further evidence for some structural compartmentalization of emotion in the cerebral hemispheres.

\section{$\underline{\text { Asymmetry in Cognition }}$}

Thus, frontal circuitry is crucial for emotion experiences but frontal circuits also mediate executive functions. Lezak and colleagues (2004) describe executive functions as the ability to self-correct, self-monitor, and learn. Executive functions involve the ability to respond in an adaptive manner to novel situations (Lezak, Howieson, \& Loring, 2004), and similar to other cognitive tasks, some executive functions are lateralized. That is, it has been long established that laterality exists during cognitive tasks, with verbal and sequential skills related to left hemisphere function, while visuospatial and holistic skills are processes of the right hemisphere (Gordon, 1986); these lateralization patterns appear to be true for some executive functions as well (Baldo et al., 2001).

Fluency tasks, which involve verbal or visual initiation, self-regulation, and cognitive flexibility, are commonly used to assess executive functioning (Lezak et al., 2004). Verbal and figural fluency tasks require the ability to produce, quickly, unrepeated words (verbal fluency) or drawings (figural fluency) while adhering to a list of rules about acceptable and unacceptable responses. Since these tasks are available to assess verbal and non-verbal abilities, they are ideally suited to investigate cognitive lateralization in executive functions (Delis, Kaplan, \& Kramer, 2001).

Imaging data indicate asymmetry during fluency tasks, with greater left versus right frontal activation during a phonemic fluency task (Billingsley et al., 2004), specifically in the left prefrontal cortex (Audenart et al., 2000; Schlosser et al., 1998), an important region for generating semantic and non-semantic words (Costafreda et al., 2006; Gabrieli, Poldrack, \& 
Desmond, 1998; Paulesu et al., 1997; Phelps, Hyder, Blamire, \& Shulman, 1997). Thus, similar to PA, verbal fluency is a task that is associated with left frontal activation (Butler, Rorsman, Hill, \& Tuma, 1993; Cuenod et al., 1995; Laine, 1988; Perret, 1974).

During design fluency tasks, activation is observed in right frontal circuitry, similar to the greater right frontal activation seen when an individual experiences NA (Jones-Gotman, 1991; Jones-Gotman \& Milner, 1977). Findings have generally shown impaired figural fluency to be indicative of right anterior dysfunction, such as right frontal lobe lesions (Ruff, Allen, Farrow, Niemann, \& Wylie, 1994). Lesion studies also support overall results of asymmetry findings during fluency tasks; verbal fluency is typically impaired in patients with left frontal lobe lesions, whereas patients with right hemisphere lesions exhibit deficits in figural fluency, among other things (Baldo et al., 2001). Studies of cerebral blood flow during verbal and spatial tasks have shown greater relative cerebral blood flow in the left than right frontal hemisphere during verbal tasks and greater relative cerebral blood flow in the right than left frontal hemisphere during spatial tasks (Gur et al., 1987). fMRI studies support these findings as greater left dorsal amygdala response was observed when participants were exposed to verbal stimuli and right dorsal amygdala response after being exposed to pictoral stimuli (Kensinger \& Schacter, 2006).

\section{Emotion and Cognition}

Thus, the lateralized neuroanatomy underlying emotion and executive function is overlapping; as previously discussed, there is robust evidence that frontal circuits differentially mediate the processing of emotion and some executive functions, which may provide a mechanism for interactions between emotion and cognition. Previous findings support associations between differentially lateralized emotion and cognitive performance. Gray (2001) found lateralized associations between emotion and working memory, which is an executive 
function. In this study, individuals with induced positive mood performed better when asked to immediately recall verbally presented letters than on a spatial task, whereas participants in the negative mood group performed better on the spatial than the verbal task (Gray, 2001). Thus, induced positive emotion elicited greater verbal working memory performance while negative mood was associated with greater spatial working memory performance.

Previous research also investigated potential associations between PA and verbal fluency performance. Greene and Noice (1988) reported that induced PA increased verbal fluency in adolescents. Moreover, greater positive mood has been shown to be positively associated with greater words produced during a phonemic fluency task in young and middle-aged adults (Phillips, Bull, Adams, \& Fraser, 2002). These data, along with Gray (2001), integrate previous research that found increased left hemisphere activation both during verbal fluency tasks and during positive mood states, and greater right hemisphere activation during figural fluency tasks and negative mood states (Allen \& Kline, 2004; Audenart et al., 2000; Billingsley et al., 2004; Butler et al., 1993; Cacioppo, 2004; Cuenod et al., 1995; Davidson et al., 1990; Davidson et al., 1990; Davidson, 1998; Davidson, 2001; Davidson, 2004; Heller, 1993; Heller et al., 1997; Heller \& Nitschke, 1998; Heller et al., 1998; Herrington et al., 2005; Jackson et al., 2003; Laine, 1998; Lee et al., 2004; Perret, 1974; Schlosser et al., 1998).

In the first experimental test of associations between emotion and fluency performance, Bartolic and colleagues (1999) sought to investigate the effects of induced mood on verbal and figural fluency tasks. Participants completed a number of subtests from figural and phonemic tests before the investigators induced positive or negative mood states. This particular mood induction experiment followed the Velten Mood Induction Procedure (Velten, 1968), which has been used extensively in past research (e.g., Finegan \& Seligman, 1995; Knight, Maines, \& 
Robinson, 2002; Perlotto, 2007). First, participants were assigned to positive or negative mood groups. Participants were aurally and visually presented with words starting with neutral words and gradually becoming more emotionally valenced. Participants then read the words once to themselves and once aloud and were asked to experience the particular emotion related to the words. Mood induction was verified by significant changes in self-reported moods before and after induction. Participants then completed the remaining fluency tasks. After positive mood induction, participants performed better on verbal fluency tasks than figural fluency, whereas participants who experienced negative induced mood demonstrated better figural than verbal fluency performances (Bartolic et al., 1999). These results suggest that greater left hemisphere activation that accompanies positive mood may contribute to better performance during verbal fluency, a task shown to be mediated by the left frontal circuitry; the inverse may have occurred during negative mood induction, where right hemisphere activation due to negative mood increased figural fluency performance.

\section{Cognitive and Emotion Changes in Aging}

Although cerebral lateralization in emotion and cognition has been observed in younger (Bartolic et al., 1999) and midlife adults (Phillips et al., 2002), the bulk of the studies reviewed thus far did not include older adults when investigating lateralization in emotion. However, age may be an important factor to consider in studies of lateralization because one theory argues that a lateralized activation during cognitive tasks is lesser in older than younger adults (Cabeza et al., 1997; Cabeza, 2001, 2002). In fact, cognitive changes that accompany normal aging argue against a similar lateralized organization in older compared to younger persons.

That is, it is well-established that decline in some cognitive abilities occurs with age. This decline is observed in areas such as working memory, memory retrieval, and visual spatial 
abilities (Greenwood, 2000). Age-related cognitive decline may be due to atrophy, which occurs in many areas of the brain as a part of normal aging, but is especially notable in frontal circuitry (Pfefferbaum, Adalsteinsson, \& Sullivan, 2005; Tisserand et al., 2004). One hypothesis suggests that because of atrophy, cognitive performance in older adults does not demonstrate the same prefrontal asymmetry as observed in healthy younger adults (Cabeza et al., 1997; Cabeza, 2001, 2002). Cabeza's (2002) model, Hemispheric Asymmetry Reduction in Old Adults (HAROLD), suggests that older relative to younger adults tend to employ more bilateral resources, especially notable in the prefrontal cortex, when completing a variety of cognitive tasks. Furthermore, results show that older individuals who demonstrate bilateral prefrontal activation tend to perform better on cognitive tasks than older individuals who show an asymmetrical profile. For example, older adults who demonstrated greater bilateral prefrontal cortical activity performed faster on a verbal working memory task than older adults who did not exhibit bilateral activation (Reuter-Lorenz, et al., 2000), providing support for the idea that older adults may utilize bilateral resources to compensate for age-related neurodegeneration (Cabeza et al., 1997; Cabeza, 2001, 2002). Thus, many findings related to cerebral asymmetry from studies with younger persons may not be relevant for older adults.

As previously mentioned, less is known about lateralization in emotion in older adults, although one study found that older women who smelled an odor and rated it more positively showed relatively greater left frontal activation compared to those who rated odors as more negative or neutral (Kline, Blackhart, Woodward, Williams, \& Schwartz, 2000). Clearly, more data are needed to better understand if and how age-related reductions in asymmetry impact cognition and/or emotion. 
However, previous research suggests differences with regard to emotional development across the lifespan. Particularly, it is a robust finding that as individuals age, there is a decline in NA, whereas PA tends to remain stable or slightly increase over time (Consedine \& Magai, 2006; Griffin, Mroczek, \& Spiro, 2006; Mather \& Carstensen, 2005; Kunzmann, Little, \& Smith, 2000). Older adults tend to report greater control over NA (Consedine \& Magai, 2006). That is, as individuals age, there appears to be an increased capacity to regulate NA experiences and expressions; over time, this regulatory ability tends to be proactive, going into effect before negative emotions are aroused (Consedine \& Magai, 2006). In studies of memory recall of positive and negative images, older adults tend to recall significantly less negative and more positive images compared to younger adults (Mather \& Carstensen, 2005). This may be a protective mechanism, termed the "positivity effect" related to the decrease in NA observed in older adults (Mather \& Carstensen, 2005). This difference in emotional development across different age groups raises compelling questions about how these differences may affect associations between emotion and cognition among age groups.

\section{The Current Study}

It is the aim of the current study to build on the existing literature regarding emotion and executive functions. Past research demonstrated improved verbal fluency performance with induced positive mood and improved figural fluency performance with induced negative mood (Bartolic et al., 1999) and the present study aims to discover if similar results will be observed in the context of daily, naturalistic mood states.

Our first hypothesis is that there will be associations between mood and performance on fluency tasks. Specifically, PA will be positively and more strongly associated with verbal than figural fluency performance, whereas NA will be more positively and strongly associated with 
performance on figural than verbal fluency. These hypotheses pertain mainly to young and middle-aged adults because we expect different findings in older persons. That is, we also seek to investigate whether there is an age-related moderator of the association between emotion and executive function, since older adults may employ more bilateral prefrontal resources when completing cognitive tasks (Cabeza et al., 1997; Cabeza, 2001, 2002). Due to potentially lesser cerebral asymmetry in older adults, our second hypothesis is that we expect a weak or absent association between mood and lateralized performance on fluency tasks in older adults.

This study has important practical and clinical implications because it seeks to explore associations between emotion and executive functioning. It is of great importance to investigate factors that may potentially influence cognitive abilities, since they are important abilities for day-to-day functioning. That is, determining if and when one's cognitive abilities may be enhanced or degraded can provide useful information for assessing when cognitive performance may be at its best. Investigation of potential age differences in associations between emotion and executive functioning could result in a better understanding of whether associations between the two are enhanced or degraded at different ages. Furthermore, a better understanding of cerebral organization at different ages is clinically relevant as it provides information about the effectiveness of assessing laterality. Although past research has shown the effects of induced mood on executive functioning, this study appears to be the first of its kind to investigate how everyday mood states may influence executive functioning. An understanding of potential interplay between everyday mood states and executive functioning may provide useful information for how individuals' daily moods may be affecting their cognitive performance. 


\section{CHAPTER II}

\section{METHOD}

\section{$\underline{\text { Participants }}$}

Data for this study are from a broader project investigating how cognitive and motivational factors affect emotional self-knowledge across the life span. Data collection began in the fall of 2006 and was completed in the fall of 2007. Participants were younger (aged 20 to 39 years), middle-aged (aged 40-64 years), and older adults (aged 65 years and older). The older and middle-aged adults were recruited from the western Massachusetts area through posters, fliers, advertisements in newspapers, and talks at various community organizations. Individuals from an IRB-approved participant pool of older adults also were contacted for participation. The younger adults are University of Massachusetts undergraduate students recruited through an online sign-up for Psychology experiments.

Inclusion criteria required participants to be in good to excellent self-reported health, have the ability to travel to the campus for participation in the study, be English-speaking, have had at least nine years of formal education, and have the ability to participate in computerized testing. Exclusion criteria included a current or past neurologic illness, current or past major psychiatric diagnoses, current or past diagnoses of substance abuse or dependence, or cognitive impairment. The older and middle-aged adults were reimbursed $\$ 25$ for their time and the undergraduate students received extra credit points for participation.

\section{$\underline{\text { Procedure }}$}

All participants were screened for inclusion and exclusion criteria over the telephone by a trained undergraduate research assistant, using the Telephone Interview for Cognitive Statusmodified (TICS-M) (Welsh, Breitner, \& Magruder-Habib, 1993); qualifying individuals were 
invited to participate. In individual assessment sessions, all participants signed an IRB-approved consent form before taking part in the study. As a part of data collection for the larger study, each participant completed a computerized assessment of self-report emotion, as well as verbal and figural fluency tasks administered by a trained undergraduate research assistant.

\section{$\underline{\text { Measures }}$}

\section{Emotion Judgment Task}

Participants responded to positive and negative emotion items presented on a computer screen. Using the computer keyboard, participants rated the extent to which they experienced each emotion based on a Likert-type rating scale $(1=$ none; $5=$ an extreme amount $)$ for two time frames, today and in general. There were 30 positive (e.g., confident, delighted) and 30 negative (e.g., disappointed, angry) items (see Appendix for a complete list of the adjectives used). Each item was presented for both time frames in order to obtain information on participants' state and trait ratings of emotion, respectively. Each participant completed two trials for each time frame resulting in responses for 240 words total, contributing to increased reliability scores (Ready, Robinson, \& Weinberger, 2006; Ready \& Robinson, accepted for publication). In previous research, the measure had strong internal consistency reliability for each valence (positive/negative) among older and younger adults (Cronbach's $\alpha$ ranged from .97-.98 for younger and older adults), suggesting that older adults did not experience difficulty with the computerized nature of the test (Ready et al., 2006).

This test has been used in the past and validated in previous studies (Ready \& Robinson, under review; Ready et al., 2006; Robinson \& Barrett, 2007; Robinson \& Kirkeby, 2005; Robinson, Ode, Moeller, \& Goetz, 2007). For example, results from this test correspond with the Satisfaction with Life Scale (Diener, Emmons, Larsen, \& Griffin, 1985). Individuals who 
endorsed greater life satisfaction demonstrated stronger associations among positive emotions and weaker associations among negative emotions (Robinson \& Kirkeby, 2005; Robinson \& von Hippel, 2006). Furthermore, individuals higher on life satisfaction reported significantly more intense experiences of positive affect (Robinson \& Kirkeby, 2005).

Subtests from the Delis-Kaplan Executive Function System (DKEFS)

Two executive functioning tasks were used to assess lateralized cognition, The Verbal Fluency Test and The Figural Fluency Test from the DKEFS (Delis, Kaplan, \& Kramer, 2001; Delis, Kramer, Kaplan, \& Holdnack, 2004). Normative data from the DKEFS manual were used to calculate standardized age-corrected scores.

The Verbal Fluency Test requires participants to name as many words as possible that begin with a particular letter (i.e., F, A, S) in three one-minute intervals. Participants are asked to name as many words in each category with the exception of proper names (e.g. names, locations, etc.), numbers, or words that are variants of an original word (e.g. fast, faster), without repeating it during the same trial (Delis et al., 2001). Scores are based on the number of correct words produced during each trial. Executive functions assessed during this test include phonological retrieval and simultaneous processing and monitoring (Delis, Kaplan, \& Kramer, 2001). Results of split-half correlations found the Verbal Fluency task to have moderate to high internal consistency reliability ( $r=.68$ to .90$)$; the test also exhibits high test-retest reliability $(r=.80)$, with retest time frames ranging from nine to 74 days ( $M=25$ days) (Delis et al., 2001; Homack, Lee, \& Riccio, 2005).

The Figural Fluency Test requires participants to draw as many original, non-nameable and non-scribbled figures as possible. There are five one-minute trials. Participants are instructed to create original designs by connecting filled circles, connecting empty circles, and by 
alternating between filled and empty circles. Scores are calculated based on the number of original designs produced during each trial. Executive functions measured by this test include problem solving behavior, fluency of visual designs, creativity, and inhibition (of reconstructing previously drawn designs) (Delis et al., 2001). Although there is a motor component to design fluency, previous research found no correlation between figural fluency and motor performance (Ruff et al., 1994). Thus, it can be assumed that the primary domain assessed by design fluency is executive function. Test-retest reliability $(M=25$ days, $S D=12.8)$ showed low reliability for all three trials; filled dots only $(r=.58)$, empty dots only $(r=.57)$, and for design switching $(r=$ .32). The authors of this test argue that low reliability on this task should not pose a serious concern, as high reliability is difficult to attain in tests of executive functioning (Delis et al., 2001). That is, greater variability is anticipated because DKEFS subtests tap a complex array of cognitive processes that are demanded by executive functioning tasks (Delis et al., 2001).

\section{$\underline{\text { Analyses }}$}

Preliminary analyses were run to characterize the sample. Two separate one-way analysis of variances (ANOVAs) were conducted to assess age group differences between verbal and figural fluency. We expected there would be age-related differences in raw scores for fluency performance because of well-documented age-related declines in executive functions (Bryan \& Luszcz, 2000; Daigneault \& Braun, 1993). To identify age group differences between PA and NA, two separate one-way ANOVAs were conducted. Based on previous findings (Consedine \& Magai, 2006; Griffin, Mroczek, \& Spiro, 2006; Kunzmann, Little, \& Smith 2000), we expected that older adults would report lower NA than younger and middle-aged adults.

Analytic Considerations 
There were many considerations as to which variables, and in which format, to include in primary analyses. Specifically, there was the choice to focus on raw or age-corrected executive function scores, the decision to treat age as a continuous or categorical variable, and the decision to treat self-reported affect for today and in general separately or to aggregate across time frame. Our decisions and rationale are discussed below.

This study seeks to investigate potential age group differences in the associations between executive functioning and affect, and not in mean level differences between the groups; thus, analyses included raw rather than age-corrected values from the executive functioning and affect scores, even though there may be age-related mean level differences for these scores. However, for the sake of complete reporting and thorough understanding of the data, we also ran analyses with age-corrected executive function scores; results are reported in a footnote. As for self-reported affect, we planned to test the correlations between PA for today and in general and also between NA rated today and in general. If data for the two time frames were highly intercorrelated (i.e., $r \mathrm{~s}>.80$ ), we planned to aggregate self-reported affect for PA and NA across time frame. If the time frames were not highly correlated enough for aggregation, then we planned to run analyses separately on ratings for today and in general.

Finally, we considered how to treat the age variable. This was a difficult decision because age is treated both as a continuous and categorical variable in adult lifespan research. However, since our hypotheses are based on differences between age groups, our primary analytic strategy was to use age as a categorical variable. We ran analyses with 3- (i.e., younger, middle-aged, older) and 2-groups (i.e., younger/middle-aged, older), since we expected the two younger groups to differ from the oldest. However, since treating age as a continuous variable can often be more powerful than group-based approaches, all analyses also were run treating age 
as a continuous variable and results of these (i.e., age-continuous) analyses are reported in a footnote. Again, our multiple analytic strategies were in the spirit of achieving the fullest understanding of the associations in our data.

\section{Analyses to Test Hypothesis One}

To determine associations between emotion and fluency, four linear multiple regression analyses were run, with emotion (i.e., either PA or NA) as the dependent variable and fluency performance (i.e., verbal or figural fluency) as the independent variable. These analyses investigated whether verbal fluency performance was significantly associated with PA and whether figural fluency performance was significantly associated with NA. To gain a better understanding of our results, we also investigated whether figural fluency performance was significantly associated with PA, and whether verbal fluency performance was significantly associated with NA. If the regression coefficients for fluency were significant, then the respective emotion would be significantly associated with fluency performance.

\section{Analyses to Test Hypothesis Two}

To test the second hypothesis that age moderates the association between fluency performance and emotion, four moderated multiple regression analyses were conducted with age, fluency performance, and their interaction as independent variables, and emotion as the dependent variable. Specifically:

$$
\begin{aligned}
& \mathrm{PA}=\alpha+\beta_{1} * \text { age }+\beta_{2} * \text { verbal fluency }+\beta_{3} * \text { (age } \mathrm{x} \text { verbal fluency) }+ \text { error } \\
& \mathrm{NA}=\alpha+\beta_{1} * \text { age }+\beta_{2} * \text { verbal fluency }+\beta_{3} *(\text { age } \mathrm{x} \text { verbal fluency })+\text { error } \\
& \left.\mathrm{PA}=\alpha+\beta_{1} * \text { age }+\beta_{2} * \text { figural fluency }+\beta_{3} * \text { (age } \mathrm{x} \text { figural fluency }\right)+ \text { error } \\
& \left.\mathrm{NA}=\alpha+\beta_{1} * \text { age }+\beta_{2} * \text { figural fluency }+\beta_{3} * \text { (age } \mathrm{x} \text { figural fluency }\right)+ \text { error }
\end{aligned}
$$


If the regression coefficients for the interaction terms in these models (i.e., $\beta_{3}$ ) were significant, after controlling for main effects, then the association between emotion and fluency performance varied by age group. 


\section{CHAPTER III}

\section{RESULTS}

\section{$\underline{\text { Sample }}$}

The sample was comprised of 74 participants with 24 younger $(66.70 \%$ female; $M$ age $=$ 19.5 years, $S D=1.25), 22$ middle-aged $(90.90 \%$ female; $M$ age $=57.86$ years, $S D=4.75)$, and 28 older adults $(57.10 \%$ female; $M$ age $=73.11$ years, $S D=6.08)$; a chi-square test for age group differences in gender indicated significant differences between the groups $\left(\chi^{2}(2, N=74)=6.95\right.$, $p<.05)$. The ethnic make up of younger adults was Caucasian $(70.80 \%)$, Asian-American (16.70\%), and Hispanic (12.50\%); for middle-aged adults, Caucasian (100\%); and for older adults, Caucasian (92.90\%), African-American (3.57\%), and Native American (3.57\%). A chisquare test for age group differences in ethnicity indicated significant differences between the groups $\left(\chi^{2}(8, N=74)=19.10, p<.05\right)$. To test for age-group differences in cognition, education, and income, three one-way analysis of variances (ANOVAs) were conducted. Results indicated that the groups did not significantly differ with regard to general cognitive functioning $($ TICS; $F(2,70)=1.21, p>.35)$ or annual household income $(F(2,70)=.16, p>.80$; Table 1$)$. However, there were significant age group differences for education $(F(2,62)=5.31, p<.01)$. Tukey's post-hoc contrasts indicated that younger adults completed significantly $(p<.05)$ fewer years of education than middle-aged and older adults; however, all younger adults were current university undergraduates and had not yet completed their educational careers.

\section{Internal Consistency Reliability of Affect Measures}

Internal consistency reliabilities for self-reported affect measures generally were strong for the entire sample (Table 2). However, the reliabilities were slightly weaker in older compared to middle-aged and younger adults, particularly for NA in general ratings. 


\section{Age Group Differences on Executive Function Tasks and Emotion Self-report}

To test for age-group differences on independent and dependent variables, a number of one-way ANOVAs were conducted. Age groups did not differ with regard to letter fluency raw scores $(F(2,72)=2.06, p>.10$; Table 1$)$, which was somewhat surprising given that reliable age group differences are found on most executive function measures (Bryan \& Luszcz, 2000; Daigneault \& Braun, 1993), including verbal fluency (Kempler, Teng, Dick, Taussig, \& Davis, 1998). However, the age groups differed on design fluency performance $(F(2,71)=5.02, p<$ .01). Tukey's post-hoc contrasts indicated that middle-aged adults completed significantly more designs than older adults for design fluency $(p<.01)$. Contrary to expectations, there were no significant group differences on self-reported affect of either valence for either time frame on the Emotion Judgment Task, although there was a trend for an age group difference for PA today $(F(2,71)=2.75, p<.10)$. Tukey's post-hoc contrasts indicated a trend for older adults reporting greater PA today than younger adults. There were no significant age group differences for PA in general $(F(2,71)=.79, p>.40)$, NA today $(F(2,71)=1.38, p>.25)$, or NA in general $(F(2,71)$ $=.65, p>.45)$.

\section{Correlations between Affect Scores}

To determine associations between self-reported affect for the two time frames (i.e., today and in general), correlations were calculated. Results revealed a significant, strong, and positive correlation between PA ratings for today and in general $(r=.90, p<.01)$, as well as between NA ratings for today and in general $(r=.82, p<.01)$. Since day and general ratings were significantly, positively, and strongly correlated within each valence, the two time frame ratings were averaged into a combined value for primary analyses. However, analyses also were 
run separately by today and in general time frames for both valences to determine if results did not differ by time frame; results of time frame analyses are presented in a footnote.

\section{Correlations between Outcome and Predictor Variables}

For the entire sample, correlations between affect and fluency performance revealed no significant associations (Table 3). Correlations also were calculated separately by age group and no significant correlations between affect and fluency were observed in the younger, middleaged, or older adult groups. These results were not consistent with our expectations because we anticipated significant, positive correlations between verbal fluency and PA and between figural fluency and NA.

In general, there were small to moderate, negative associations between self-reported PA and NA (Table 3), which is generally consistent with previous research (Watson, Clark, \& Tellegen, 1988). Thus, whereas there were significant associations between PA and NA, the measures appear to be sufficiently independent to support separate analyses by valence. There also were small to large positive correlations between the two fluency measures, which was not surprising because both design and verbal fluency are executive functioning measures and thus tap different aspects of the same construct.

It is interesting to note, however, that the correlations between affect and fluency measures tended to be stronger for older than midlife persons. We sought to determine if the correlations were significantly different. First, the correlations were transformed into $z$-scores by a Fisher $r$ - to- $z$ transformation; next, the difference between the $z$-scores was determined with a $t$ test. Results indicated that the differences in correlations for older and midlife persons were not significant for affect $(t(21)=-1.42, p>.10)$ or for fluency measures $(t(21)=1.71, p>.10)$.

\section{Linear Regressions: Analyses to Test Associations between Affect and Fluency Performance}


To review, linear regressions were run to determine the associations between fluency and affect. Fluency scores (i.e., verbal fluency raw and design fluency raw) were the independent variables and averaged affect scores (i.e., PA and NA) were the dependent variables.

In the first regression, verbal fluency was entered as a predictor for PA; results showed a trend $(p<.10)$ for verbal fluency performance to be positively associated with PA (Table 4), which partially supports our hypotheses. Next, verbal fluency was entered as a predictor for NA. There was no significant association between verbal fluency and NA, which was consistent with our hypothesis. The next regression tested if design fluency was significantly associated with PA. Results indicated no significant association between design fluency and PA, consistent with our hypothesis that design fluency performance would not be significantly associated with PA. The final linear regression tested if design fluency was significantly associated with NA. Contrary to our hypothesis, results showed that design fluency was not significantly associated with $\mathrm{NA}^{1}$.

In summary, although no significant effects were found in support of our hypothesis that verbal fluency would be associated with PA, a trend in that direction was observed. Furthermore, in support of our hypotheses, no significant associations were observed between verbal fluency and NA or between figural fluency and PA. However, contrary to expectations, no significant effect, or even a trend, was noted between design fluency and NA.

\section{$\underline{\text { Moderated Multiple Regression Analyses: Analyses to Test Age as a Moderator of Associations }}$}

\section{between Affect and Fluency Performance}

As described above, four moderated regressions were conducted. The first step in these regressions included age group as an independent variable and affect as the dependent variable. In the second step in this forced stepwise regression, age group was entered as the first 
independent variable, followed by fluency performance. The third step included age, fluency performance, and the interaction between age and fluency performance as the independent variables.

Age, Verbal Fluency, and their Interaction, on PA

In the first regression, age group was entered as a predictor of PA. Results suggest a trend $(p<.10)$ for a positive association between age and PA (Table 5). In the next step, verbal fluency was entered as a predictor, following age group. Again, there was a trend for verbal fluency to be positively associated with PA. In this step, age no longer showed a trend for an association between age and PA. The final step in the moderated regression showed no significant main effects of age or verbal fluency to be associated with PA; the interaction term also was not significant.

The effects of age group on PA using two age groups (i.e., young and middle-aged combined, and older), was investigated; a trend for an association between age and PA was noted, as above $(B=.69, S E=.38, \beta=.21, p<.10)$. When verbal fluency was added as a predictor, a trend for verbal fluency to be positively associated with PA was observed $(B=.03$, $S E=.02, \beta=.21, p<.10)$. Unlike in the three age group analyses, the second step in this multiple regression continued to show a trend for age to be associated with PA $(B=.65, S E=$ $.37, \beta=.20, p<.10)$. The final step of this regression showed no significant main effects of age and verbal fluency, and the interaction term was not significant.

Thus, overall, results were partially in line with our hypothesis that better verbal fluency performance would be positively associated with greater PA. However, we also expected to find that age group would moderate the association between verbal fluency and PA but we did not 
find support for this prediction. Investigating these effects using three- versus two-age groups did not appreciably change the outcome.

Age, Design Fluency, and their Interaction, on PA

The next regression investigated whether age group, design fluency, and their interaction, were significantly associated with PA. As before, results of the first step showed a trend for age group to be positively associated with PA (Table 5). When design fluency was added in the second step, a trend for age group was still observed. No main effect or trend was noted for design fluency, nor was the interaction term significant.

Like the three age group findings, there was a trend for the two age group factor to be positively associated with PA $(B=.70, S E=.38, \beta=.21, p<.10)$. When design fluency was added to the model, a trend for age to be associated with PA also was found $(B=.79, S E=.40, \beta$ $=.24, p<.10)$, similar to that found with the three age group variable. No main effect or trend was noted for design fluency, nor was the interaction term significant. These results also are in support of our hypothesis that design fluency would not be significantly associated with PA.

Age, Verbal Fluency, and their Interaction, on NA

No significant main or interaction effects were found for age group (for 3- and 2-group approaches), verbal fluency, and their interaction to be significantly associated with NA (Table 5). This result is in line with our hypothesis that age and verbal fluency performance would not be significantly associated with NA.

Age, Design Fluency, and their Interaction, on NA

The final regression investigated whether age group, design fluency, and their interaction were significantly associated with NA. Results of the first step of the regression, whether age is associated with NA, was not significant (Table 4). In the next step, design fluency was entered as 
a predictor, following age group. There was a trend for age to be negatively associated with NA (Table 5). There was neither a significant main effect of design fluency, nor a significant interaction effect between age group and design fluency on NA in the third step of this regression.

For two age-group analyses, in the first step of this regression, age was not significantly associated with NA; however, when design fluency also was added as a predictor, trends were observed for age group $(B=-.51, S E=.30, \beta=-.21, p<.10)$, as well as design fluency $(B=-.03$, $S E=.02, \beta=-.21, p<.10)$ to be negatively associated with NA. The interaction term was not significant $^{2}$

Thus, overall findings did not support our hypotheses that there would be a significant, positive association between figural fluency and NA, nor did it support our hypothesis that this association would vary by age group ${ }^{3}$. 


\section{CHAPTER IV}

\section{DISCUSSION}

There are robust findings that link emotion processing to activity in the frontal cortex (Allen \& Klein, 2004). Specifically, cerebral asymmetry has been observed with greater left than right hemisphere activation during positive mood states, whereas negative mood states are associated with greater right than left hemisphere activation (Davidson et al., 1990). Certain cognitive tasks also demonstrate lateralized activation of similar anatomical structures. That is, verbal fluency is an executive function task mediated by the left hemisphere and figural fluency is a task mediated by the right hemisphere (Delis, et al., 2001). Whereas previous research integrated these lines of work to determine associations between induced mood and performance on lateralized cognitive tasks (Bartolic et al., 1999), the current study was the first to determine associations between normative mood states and lateralized executive functions.

\section{Associations between Verbal Fluency and PA}

In general, results were disappointing and not entirely consistent with predictions. That is, we did not find strong support for associations between putative left hemisphere tasks (i.e., positive mood and verbal fluency) or between supposed right hemisphere tasks (i.e., negative mood and figural fluency). However, there was a trend for an association between verbal fluency and PA, which is consistent with previous research (Bartolic et al., 1999; Greene \& Noice, 1988).

Potential mechanisms linking PA and verbal fluency are not known, but there are neuroanatomical similarities between the two. That is, evidence suggests that left frontal activation occurs during PA (Allen \& Kline, 2004; Cacioppo, 2004; Davidson, et al., 1990; Davidson, Eckman, Saron, Senulis, \& Friesen, 1990; Davidson, 1998; Davidson, 2001a; 
Davidson, 2004; Heller, 1993; Heller, Nitschke, \& Lindsay, 1997; Heller \& Nitschke, 1998;

Heller, Nitschke, \& Miller, 1998; Herrington et al., 2005; Jackson et al., 2003; Lee et al., 2004), as well as during verbal fluency task performance (Butler et al., 1993; Cuenod et al., 1995; Laine, 1988; Perret, 1974). Thus, associations between PA and verbal fluency could be due to increased activation of overlapping cortical areas.

With regard to theories of brain organization and emotions, our findings provide only partial support for one of the major theories. Davidson's (1990) model of cerebral lateralization, which guided hypotheses in the current study, suggests that greater left than right frontal activation is associated with positive mood, whereas right frontal activation is associated with greater negative than positive mood. Following from this, we were expecting positive associations between verbal fluency and PA and positive associations between figural fluency and NA. Our lack of support for lateralized associations between valenced emotions and cognitive tasks suggests that we did not fully support this theory. That is, we found some suggestion that PA might be positively associated with verbal fluency but no association between NA and design fluency.

Furthermore, it is important to note that our results do not support an alternative theory to Davidson's model. This other model suggests that emotion activation, regardless of valence, is associated with greater right than left hemisphere activation (Heller et al., 1998). That is, both positive and negative moods should be associated with right frontal activation, rather than lateralized activity (Heller et al., 1998). For our data to have supported this model, we would have found PA and NA to be positively associated with figural fluency; however, our results did not conform to this pattern.

\section{$\underline{\text { Age Group Differences }}$}


This study also sought to determine if and how age group might moderate associations between emotion and cognition. Contrary to expectations, there was no evidence that age had an effect on lateralized associations between cognition and emotion. However, there was some evidence hinting at decreased lateralization in emotion and cognition in older versus midlife persons. That is, correlations between PA and NA were slightly, although not significantly, stronger for older adults than they were for midlife persons, which might suggest greater interdependence and potentially less lateralization between the affect systems. A similar pattern was noted in correlations between design and verbal fluency, which were slightly stronger in older compared to middle-aged persons. Thus, while middle-aged adults may have been using more independent, lateralized cognitive areas to complete the tasks, older adults may have been using more overlapping, bilateral cerebral resources when completing fluency measures. If replicated with a larger sample, our findings might support theories pertaining to decreased lateralization with increasing age; however, differences between younger and older persons were negligible and clearly, more data with larger samples are needed to more fully address this issue.

\section{$\underline{\text { Summary of Results }}$}

In summary, our findings provide partial support for lateralized associations between emotion and fluency tasks, which have been previously observed in experimental research (Bartolic et al., 1999; Greene \& Noice, 1988). That is, associations between emotion and cognition indicated that verbal fluency may be positively associated with PA, but results did not support predictions that design fluency performance would be positively associated with NA. Furthermore, age-related predictions were not supported.

\section{$\underline{\text { Limitations }}$}


The present study had several limitations that could explain why our findings did not support the hypotheses that design fluency would be positively associated with NA and that age would moderate relationships between fluency performance and affect. First, there was a lack of expected, age-related differences among our age groups. For example, there were no age group differences on verbal fluency test performance, which was surprising because previous research suggests that executive functioning declines with age (Bryan \& Luszcz, 2000; Daigneault \& Braun, 1993), including verbal fluency (Kempler et al., 1998). Furthermore, there also were no significant age group differences on the affect measures. In line with past research, we would have expected to find lesser NA and potentially greater PA in our older adults as compared to our younger and middle-aged groups (Consedine \& Magai, 2006; Griffin et al., 2006; Kunzmann et al., 2000). Thus, perhaps our age groups are not representative of the general adult population and were not an ideal sample with which to test age-related hypotheses.

It is important to consider variability in the affect measures in our sample. Specifically, there was little variability in self-reported NA, and as expected in a healthy sample (Watson, et al., 1988), NA was low. A sample that included persons with more NA (i.e., individuals with mild to moderate depressive symptoms) might have provided for more variability in NA, and a better test of NA-related hypotheses. That is, with our current sample, there may have been restricted or inadequate range on NA to test our hypotheses.

It also is important to consider timing of data collection on the day of the assessment. The test order of our cognitive data was held constant, and thus, verbal fluency was consistently administered before the figural fluency task. Perhaps changes in task expectations or fatigue may have systematically affected figural fluency performance. Furthermore, although we were interested in the associations between fluency and affect measures, the cognitive data were not 
collected until approximately 20 or 30 minutes following the affect measure. Thus, it is possible that mood changes occurred for some participants in the interim, perhaps because of the participants' assumptions about their cognitive performances or even due to fatigue. Time of day also is an important factor to consider because research has shown that older adults perform better on a memory task in the morning, compared to younger adults who perform better in the evening (May, Hasher, \& Stoltzfus, 1993). Although our assessments were conducted during various times of the day, some persons likely participated at a time that may have not been optimal for them, which may have adversely affected their mood and/or cognitive performance. In general, however, it is not entirely clear how time of day might have affected results, since we were interested in determining differential associations between affect and cognition rather than mean-level differences in the constructs.

It also is important to explore the efficacy of the measures. The design fluency subtest has low test-retest reliability, although the authors of the DKEFS do not view low reliability on the design fluency subtest as a major concern (Delis et al., 2001). However, a more reliable fluency measure would have been more ideal to assess fluency performance. For the affect measure, results also suggest slightly decreased internal consistency reliability of the NA in general measure in older compared to younger and middle-aged adults. Results also indicated moderate intercorrelations between PA and NA and between the two fluency measures across all age groups, but especially for older adults. It might have been more ideal to have measures of PA, NA, and design and figural fluency, which exhibited weaker intercorrelations, thus providing a more independent assessment of our core constructs. That is, lateralized affect and cognitive measures that were correlated near to zero may have allowed for a more precise test of our hypotheses. 
Finally, it is important to consider that our sample was not representative of the general population. Although generally in line with the demographics of the area, our middle-aged group especially appeared fairly homogeneous and was composed of mostly Caucasian women. Furthermore, there were age group differences in education, with younger adults having significantly fewer years of education than middle-aged and older adults. Whereas the younger adult sample was comprised of undergraduates who had not yet completed their educational careers, it is possible that educational differences between groups had an impact on our results, or lack thereof. It also is important to consider that our middle-aged and older adult age groups may have been over educated as compared to the general population. That is, mean education for these groups was the equivalent of a college education. A final limitation is that the sample size may have been inadequate to test our hypotheses with sufficient power.

\section{$\underline{\text { Significance }}$}

This study, as well as the general line of research investigating associations between cognition and emotion, has important implications for daily functioning on a number of levels. Executive functioning is a foundational cognitive ability (Lezak et al., 2004) and thus gaining a better understanding of factors that may influence this ability has clinical implications. Specifically, executive functions involve a number of abilities required for independent daily functioning. Among other things, executive functioning includes the ability for planning, organizing, decision-making, set-shifting, and initiating (Lezak et al., 2004). Thus, although research has shown that induced mood can affect executive functions (Bartolic, 1999), this study contributed to this understanding by investigating whether everyday mood also can impact executive functions. We found some suggestion that positive mood may positively enhance fluency performance. If replicated, these results may have clinical implications. For example, the 
results of the current study could provide useful information for implementing techniques to improve cognition or for cognitive interventions, based on knowledge that cognition may be improved when individuals are experiencing greater PA and that low PA may be associated with poorer performance. That is, it may prove useful for individuals to be aware of when their problem solving and thinking abilities are at their best, or when they may be hindered, based on their mood; cognitive strategies could be constructed around this information.

In addition, it may be important to extend this line of work to include consideration of links between stable traits and cognition. That is, it might be useful to determine if lateralized associations between emotion and cognition generalize to cognition and personality. For example, research has found that personality traits can influence one's affect on a day-to-day level (Rusting \& Larsen, 1997). Specifically, extraversion is positively associated with PA, whereas neuroticism is positively associated with NA (Rusting \& Larsen, 1997). Because ours and previous research has found that PA might influence cognition (i.e., verbal fluency), it may be useful to consider how personality or affective traits may determine individual differences in cognitive strengths and weaknesses.

\section{$\underline{\text { Future Directions }}$}

It is important to continue this area of research to gain a better understanding of potential associations between mood and cognition because results of the current study and others (Bartolic, 1999; Greene \& Noice, 1988) have shown that there is interplay between the two. As for new research directions, some novel methods may promote a better understanding of associations between emotion and cognition. Although past research has investigated potential associations between executive functioning and emotion, less is known about lateralization in other domains of cognitive functioning. For example, some memory tasks are verbal and figural, 
demonstrating a similar lateralized organization as observed in some executive function tasks (Lezak et al., 2004). Although memory tasks generally do not show lateralized frontal activation (Davidson, 1990), it may be beneficial to explore whether the effects of lateralized emotions are associated with cognitive abilities other than executive functions.

As stated, results of the current study were only partially consistent with some previous studies and theories and thus a clearer understanding of lateralized activation occurring during emotion and cognition tasks may prove beneficial. For example, functional Magnetic Resonance Imaging (fMRI) data could provide data to gain a better understanding of lateralized brain activation during emotion and cognitive tasks. That is, perhaps it would be useful to assess for lateralized activation while the participant is completing each task. Furthermore, in part, we wanted to test a theory of lesser cerebral asymmetry in older relative to younger adults and fMRI data might be particularly useful to compare cerebral activation during lateralized tasks in older versus younger participants.

Thus, in an effort to be as thorough as possible in investigating lateralized associations, an ideal future study will also collect fMRI data while participants are completing cognitive and mood tasks. Of course, we also would correct for other limitations of the current study in this future work (e.g., measures of affect and cognition that are intercorrelated closer to zero, a more representative sampling of different age groups, counterbalanced administration of emotion and cognitive measures, a larger sample size).

\section{$\underline{\text { Conclusion }}$}

In summary, this study sought to determine whether performance on lateralized cognitive tasks would be differentially associated with everyday mood. Our results provide partial support for a predicted association between verbal fluency and PA, suggesting that positive mood may 
influence some forms of cognition. Contrary to expectations, age did not moderate associations between emotion and executive functioning, perhaps because our age groups may not have been representative of their respective cohorts and thus, the samples may have been less than ideal to test age-related hypotheses. Future studies are needed to gain a better understanding of how everyday mood states and age affect executive functioning to provide greater insight into factors that enhance and detract from cognitive performance. 
Table 1

Descriptive Statistics for Younger, Middle-Aged, and Older Adults for Demographic, Fluency, and Affect Scores

\begin{tabular}{|c|c|c|c|}
\hline & $\begin{array}{l}\text { Younger } \\
(N=24)\end{array}$ & $\begin{array}{l}\text { Middle-aged } \\
\quad(N=22)\end{array}$ & $\begin{array}{l}\text { Older } \\
(N=28)\end{array}$ \\
\hline & $M(S D)$ & $M(S D)$ & $M(S D)$ \\
\hline TICS total score & $38.96(3.28)$ & $40.05(3.97)$ & $38.70(3.41)$ \\
\hline Education (in years) & $13.79(2.73)^{\mathrm{a}}$ & $16.53(2.65)$ & $16.09(3.56)$ \\
\hline Annual Household Income & $3.68(1.99)$ & $3.45(1.99)$ & $3.79(1.34)$ \\
\hline Letter Fluency Raw & $42.25(8.53)$ & $48.41(11.21)$ & $46.54(11.18)$ \\
\hline Design Fluency Raw & $33.42(9.92)$ & $36.10(10.25)$ & $28.21(7.73)^{b}$ \\
\hline Negative Affect Average & $1.75(0.58)$ & $1.61(0.64)$ & $1.51(0.55)$ \\
\hline Positive Affect Average & $3.22(0.78)$ & $3.30(0.83)$ & $3.60(0.77)$ \\
\hline
\end{tabular}

Note. $\quad$ TICS = Telephone Interview for Cognitive Status; Intervals for Annual Household Income: $0=$ less than 10,000;

$1=10,001-20,000 ; 2=20,001-30,000 ; 3=30,001-40,000 ; 4=40,001-50,000 ; 5=50,001$ or greater.

${ }^{a}$ Tukey's post-hoc contrasts indicate value is significantly $(p<.05)$ lower for young adults than for the other two age groups. 
${ }^{\mathrm{b}}$ Tukey's post-hoc contrasts indicate value is significantly $(p<.05)$ lower for older adults than for middle-aged adults. 
Table 2

Internal Consistency Reliabilities of Emotion Judgment Task Measures

\begin{tabular}{|c|c|c|c|c|}
\hline \multicolumn{5}{|c|}{ Cronbach's Alphas } \\
\hline & $\begin{array}{l}\text { All Age Groups } \\
\quad(N=74)\end{array}$ & $\begin{array}{l}\text { Younger Adults } \\
\qquad(N=24)\end{array}$ & $\begin{array}{l}\text { Middle-Aged Adults } \\
\qquad(N=22)\end{array}$ & $\begin{array}{l}\text { Older Adults } \\
\quad(N=28)\end{array}$ \\
\hline Positive Day & .85 & .87 & .88 & .79 \\
\hline Positive General & .85 & .87 & .89 & .80 \\
\hline Negative Day & .84 & .85 & .88 & .77 \\
\hline Negative General & .82 & .84 & .89 & .67 \\
\hline
\end{tabular}


Table 3

Correlations between Fluency and Affect Scores for Younger, Middle-Aged, and Older Adults

\begin{tabular}{|c|c|c|c|c|c|c|c|c|c|c|c|c|}
\hline & \multirow[b]{2}{*}{ NA } & \multicolumn{2}{|c|}{$\begin{array}{l}\text { 1ll Age Groups } \\
(N=74)\end{array}$} & \multirow[b]{2}{*}{ NA } & \multicolumn{2}{|c|}{$\begin{array}{l}\text { Younger Adults } \\
\quad(N=24)\end{array}$} & \multicolumn{3}{|c|}{$\begin{array}{l}\text { Middle-Aged Adults } \\
(N=22)\end{array}$} & \multirow[b]{2}{*}{ NA } & \multicolumn{2}{|c|}{$\begin{array}{l}\text { Older Adults } \\
\quad(N=28)\end{array}$} \\
\hline & & $\mathrm{VF}$ & $\mathrm{DF}$ & & VF & DF & NA & VF & DF & & $\mathrm{VF}$ & DF \\
\hline PA & $-.41 * *$ & .22 & .01 & $-.40 *$ & .12 & .05 & -.21 & .33 & .04 & $-.55 * *$ & .17 & .14 \\
\hline NA & - & -.13 & -.14 & - & -.35 & -.25 & - & .10 & -.07 & - & -.13 & -.28 \\
\hline VF & & - & $.42 *$ & & - & $.49 *$ & & - & .25 & & - & $.63 * *$ \\
\hline
\end{tabular}

Note. $\mathrm{PA}=$ Positive Affect average value; $\mathrm{NA}=$ Negative Affect average value; $\mathrm{VF}=$ verbal fluency raw score, $\mathrm{DF}=\mathrm{design}$ fluency raw score

$* p<.05 ; * * p<.01$ 
Table 4

Effects of Executive Functions on Emotion Scores: Linear Regressions

\begin{tabular}{lllll}
\hline Dependent & Independent & $B$ & $S E B$ & $\beta$
\end{tabular}

Variables $\quad$ Variables

Positive Affect

$\begin{array}{llll}\text { Verbal Fluency } & .03 & .02 & .22^{+} \\ \text {Figural Fluency } & .00 & .02 & .01\end{array}$

Negative Affect

$\begin{array}{llll}\text { Verbal Fluency } & -.02 & .01 & -.13 \\ \text { Figural Fluency } & -.02 & .01 & -.14\end{array}$

Note. Positive Affect $=$ Average values of PA today and in general;

Negative Affect = Average values of NA today and in general;

Fluency values are raw scores.

${ }^{+} p<.10$ 
Table 5

Effect of Age, Executive Functions, and their Interaction on Emotion Scores: Moderated Hierarchical Regressions

\begin{tabular}{llll}
\hline & $B$ & $S E B$ & $\beta$ \\
\hline
\end{tabular}

Positive Affect

Step 1

$\begin{array}{llll}\text { Age } & .39 & .22 & .20^{+}\end{array}$

Step 2

$\begin{array}{llll}\text { Age } & .33 & .22 & .17 \\ \text { Verbal Fluency } & .03 & .02 & .19^{+}\end{array}$

Step 3

\begin{tabular}{lccc} 
Age & .29 & 1.02 & .15 \\
Verbal Fluency & .03 & .05 & .18 \\
Age x Verbal Fluency & .00 & .02 & .02 \\
\hline
\end{tabular}

Positive Affect

Step 1

$\begin{array}{llll}\text { Age } & .39 & .22 & .20^{+}\end{array}$

Step 2

$\begin{array}{llll}\text { Age } & .41 & .29 & .22^{+} \\ \text {Design Fluency } & .01 & .02 & .06\end{array}$

Step 3
Age
.25
.81
.13 
$\begin{array}{llll}\text { Design Fluency } & -.00 & .05 & -.01\end{array}$

$\begin{array}{llll}\text { Age x Design Fluency } & .01 & .03 & .10\end{array}$

Negative Affect

Step 1

$\begin{array}{llll}\text { Age } & -.24 & .16 & -.17\end{array}$

Step 2

$\begin{array}{llll}\text { Age } & -.21 & .16 & -.15 \\ \text { Verbal Fluency } & -.01 & .01 & -.11\end{array}$

Step 3

$\begin{array}{llll}\text { Age } & -.72 & .76 & -.52\end{array}$

$\begin{array}{llll}\text { Verbal Fluency } & -.04 & .04 & -.33\end{array}$

$\begin{array}{llll}\text { Age x Verbal Fluency } & .01 & .02 & .47\end{array}$

Negative Affect

Step 1

$\begin{array}{llll}\text { Age } & -.24 & .16 & -.17\end{array}$

Step 2

$\begin{array}{llll}\text { Age } & -.30 & .17 & -.22^{+} \\ \text {Design Fluency } & -.02 & .01 & -.19\end{array}$

Step 3

$\begin{array}{lccc}\text { Age } & -.24 & .59 & -.17 \\ \text { Design Fluency } & -.02 & .04 & -.16 \\ \text { Age x Design Fluency } & -.00 & .02 & -.05\end{array}$

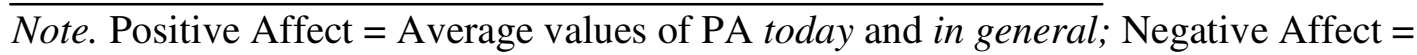


Average values of NA today and in general; Fluency values are raw scores;

Age is a categorical variable divided into three groups (young, middle-aged, and older adults). ${ }^{+} p<.10$ 


\section{APPENDIX \\ LIST OF TERMS FROM THE EMOTION JUDGMENT TASK}

Positive emotion terms were: admiration, affection, bold, brave, cheerful, confident, delighted, eager, elated, energetic, enthusiastic, excited, glad, gratified, happy, inspired, interested, joyful, lively, loving, passionate, peaceful, pleasant, pleased, positive, proud, respect, strong, thrilled, and worthy. Negative emotion terms were: afraid, agony, angry, annoyed, anxious, ashamed, bitter, blue, dejected, depressed, disappointed, distressed, down, fearful, frightened, gloomy, guilty, hostile, irritable, jittery, lonely, miserable, moody, nervous, regret, sad, scared, stressed, upset, and worried. 


\section{FOOTNOTES}

1 Analyses also were run with affect scores separately by time frame. Results were the same as those reported, except for a significant main effect for verbal fluency to be significantly associated with PA in general $(B=.02, S E=.01, \beta=.25, t=2.17, p<.05)$. Analyses also were run using age-corrected executive functioning scores. Results were the same as those reported except for significant main effects for verbal fluency to be positively associated with PA $(B=$ $.12, S E=.06, \beta=.24, p<.05)$ and for design fluency to be negatively associated with NA $(B=-$ $.03, S E=.02, \beta=-.24, p<.05)$. Thus, results of age-corrected analyses suggest significant, positive associations between verbal fluency and PA, but significant, negative associations between design fluency and NA.

2 All regressions also were run using age as a continuous variable, and no notable differences in results were observed. Furthermore, tolerance statistics in all multiple regressions suggested possible collinearity between age and fluency performance (all tolerance statistics before centering ranged from $<.10$ to .90 but all increased to .95 or greater, after centering). After centering the fluency and age variables, and their interaction, in order to increase the tolerance statistic and to control for collinearity, no changes in any results occurred.

3 All multiple regressions were re-run with affect scores separately by time frame. All results were the same, except for the following. A significant main effect was found for age group (3group variable) to be positively associated with PA today $(B=.25, S E=.11, \beta=.25, p<.05)$. In the multiple regression that investigated whether age, design fluency, and their interaction would be associated with PA, a significant main effect was found for age group to be significantly associated with PA today $(B=.25, S E=.11, \beta=.25, p<.05)$. A significant main effect also was observed for age to be negatively associated with NA today $(B=-.18, S E=.09, \beta=.24, p<.05)$. 
Thus, consistent with previous findings (Consedine \& Magai, 2006; Griffin, Mroczek, \& Spiro, 2006; Kunzmann, Little, \& Smith 2000), age was positively associated with PA and negatively associated with NA.

Analyses also were run with fluency age-corrected scores. All results were the same, except a trend was found for design fluency to be negatively associated with NA $(B=-.03, S E=$ $.02, \beta=-.22, p<.10)$. Thus, analyses with age-corrected values suggest that increased NA may be associated with worse design fluency performance. 


\section{REFERENCES}

Allen, J.J.B., \& Kline, J.P. (2004). Frontal EEG asymmetry, emotion, and psychopathology: The first, and the next 25 years. Biological Psychology, 67, 1-5.

Ashby, F.G., Isen, A.M., \& Turken, A.U. (1999). A neuropsychological theory of positive affect and its influence on cognition. Psychological Review, 106, 529-550.

Baldo, J.V., Shimamura, A.P., Delis, D.C., Kramer, J. \& Kaplan, E. (2001). Verbal and design fluency in patients with frontal lobe lesions. Journal of the International Neuropsychological Society, 7, 586-596.

Bartolic, E.I., Basso, M.R., Schefft, B.K., Glauser, T., \& Titanic-Schefft, M. (1999). Effects of experimentally-induced emotional states on frontal lobe cognitive task performance. Neuropsychologia, 37, 677-683.

Billingsley, R.L., Simos, P.G., Castillo, E.M., Sarkari, S., Breier, J.I., Pataraia, E., \& Papanicolaou, A.C. (2004). Spatio-temporal cortical dynamics of phonemic and semantic fluency. Journal of Clinical and Experimental Neuropsychology, 26, 1031-1043.

Blanchard-Fields, F. (2005). Introduction to the special section on emotion-cognition interactions and the aging mind. Psychology and Aging, 20, 539-541.

Bryan, J. \& Luszcz, M.A. (2000). Measurement of executive function: Considerations for detecting adult age differences. Journal of Clinical and Experimental Neuropsychology, $22,40-55$.

Bush, G., Luu, P., \& Posner, M. (2000). Cognitive and emotional influences in anterior cingulated cortex. Trends in Cognitive Sciences, 4, 215-222.

Butler, R.W., Rorsman, I., Hill, J.M., \& Tuma, R. (1993). The effects of frontal brain impairment on fluency: Simple and complex paradigms. Neuropsychology, 7, 519-529.

Cabeza, R. (2002). Hemispheric asymmetry reduction in older adults: The HAROLD model. Psychology and Aging, 17, 85-100.

Cabeza, R. (2001). Cognitive neuroscience of aging: Contributions of functional neuroimaging. Scandinavian Journal of Psychology, 42, 277-286.

Cabeza, R., Grady, C.L., Nyberg, L., McIntosh, A.R., Tulving, E., Kapur, S., Jennings, J.M., Houle, S., \& Craik, F.I.M. (1997). Age-related differences in neural activity during memory encoding and retrieval: A positron emission tomography study. Journal of Neuroscience, 17, 391-400. 
Coan, J.A., \& Allen, J.J.B. (2003). The state and trait nature of frontal EEG asymmetry in emotion. In: K. Hugdahl \& R.J. Davidson (Eds.), The asymmetrical brain (pp. 565-615). Cambridge, MA: MIT Press.

Consedine, N. S., \& Magai, C. (2006). Emotional development in adulthood: A developmental functionalist review and critique. In C. Hoare (Ed.), Handbook of adult development and aging (pp. 123-148). New York: Oxford University Press.

Costafreda, S.G., Fu, C.H.Y., Lee, L., Everitt, B., Brammer, M.J., \& David, A.S. (2006). A systematic review and quantitative appraisal of fMRI studies of verbal fluency: Role of the left inferior frontal gyrus. Human Brain Mapping, 27, 799-810.

Cuenod, C.A., Bookheimer, S.Y., Hertz-Pannier, L., Zeffiro, T.A., Theodore, W.H., \& Le Bihan, D. (1995). Functional MRI during word generation, using conventional equipment: A potential tool for language localization in the clinical environment. Neurology, 45, 18211827.

Daigneault, S., \& Braun, C.M.J. (1993). Working memory and the self-ordered pointing task: Further evidence of early prefrontal decline in normal aging. Journal of Clinical and Experimental Neuropsychology, 15, 881-895.

Davidson, R.J. (1995). Cerebral asymmetry, emotion, and affective style. In: R.J. Davidson, \& K. Hugdahl. (Eds.). Brain asymmetry (pp. 361-387). Cambridge: MIT Press.

Davidson, R.J. (1998). Affective style and affective disorders: Perspectives from affective neuroscience. Cognition and Emotion, 12, 307-330.

Davidson, R.J. (2001a). The neural circuitry of emotion and affective style: Prefrontal cortex and amygdala contributions. Social Science Information, 40, 11-37.

Davidson, R.J. (2001b). Toward a biology of personality and emotion. Annals of the New York Academy of Sciences, 935, 191-207.

Davidson, R.J. (2004). Anxiety and affective style: Role of the prefrontal cortex and amygdala. Biological Psychiatry, 51, 68-80.

Davidson, R.J. (2004). What does the prefrontal cortex "do" in affect: Perspectives on frontal EEG asymmetry research. Biological Psychology, 67, 219-233.

Davidson, R.J., Chapman, J.P., Chapman, L.J., \& Henriques, J.B. (1990). Asymmetrical brain electrical activity discriminates between psychometrically-matched verbal and spatial cognitive tasks. Psychophysiology, 27, 528-543.

Davidson, R.J., Ekman, P., Saron, C.D., Senulis, J.A., \& Friesen, W.V. (1990). Approach/withdrawal and cerebral asymmetry: Emotional expression and brain physiology. International Journal of Personality and Social Psychology, 58, 330-341. 
Davidson, R.J. \& Fox, N.A. (1982). Asymmetrical brain activity discriminates between positive and negative affective stimuli in human infants. Science, 218, 1235-1237.

Delis, D.C., Kaplan, E., \& Kramer, J.H. (2001). The Delis Kaplan Executive Function System. San Antonio, TX: The Psychological Corporation.

Delis, D.C., Kramer J.H., Kaplan, E. \& Holdnack, J. (2004). Reliability and validity of the DelisKaplan Executive Function System: An update. Journal of the International Neuropsychological Society, 10, 301-303.

Diener, E., Emmons, R.A., Larsen, R.J., \& Griffin, S. (1985). The satisfaction with life scale. Journal of Personality Assessment, 49, 71-75.

Finegan, J.E. \& Seligman, C. (1995). In defense of the velten mood induction procedure. Canadian Journal of Behavioural Science, 27, 405-419.

Gabrieli, J.D.E., Poldrack, R.A., \& Desmond, J.E. (1998). The role of left prefrontal cortex in language and memory. Proceedings of the National Academy of Sciences, 95, 906-913.

Goodwin, A.M., \& Williams, J.M.G. (1982). Mood induction research: Its implications for clinical depression. Behavior Therapy Research, 20, 373-382.

Gordon, H.W. (1986). The cognitive laterality battery: Tests of specialized cognitive function. International Journal of Neuroscience, 29, 223-244.

Gray, J.R. (2001). Emotional modulation of cognitive control: Approach-withdrawal states double-dissociate spatial from verbal two-back task performance. Journal of Experimental Psychology: General, 130, 436-452.

Greene, T.R. \& Noice, H. (1988). Influence of positive affect upon creative thinking and problem solving in children. Psychological Reports, 63, 895-898.

Greenwood, P.M. (2000). The frontal aging hypothesis evaluated. Journal of the International Neuropsychological Society, 6, 705-726.

Griffin, P.W., Mroczek, D.K., \& Spiro, A. (2006). Variability in affective change among aging men: Longitudinal findings from the VA normative aging study. Journal of Research in Personality, 40, 942-965.

Gur, R.C., Gur, R.E., Obrist, W.D., Skolnick, B.E., \& Reivich, M. (1987). Age and regional cerebral blood flow at rest and during cognitive activity. Archives of General Psychiatry, 44, 617-621. 
Harmon-Jones, E., \& Allen, J.J.B. (1998). Anger and frontal brain activity: EEG asymmetry consistent with approach motivation despite negative affective valence. Journal of Personality and Social Psychology, 74, 1310-1316.

Heller, W. (1993). Neuropsychological mechanisms of individual differences in emotion, personality, and arousal. Neuropsychology, 7, 476-489.

Heller, W. \& Nitschke, J.B. (1998). The puzzle of regional brain activity in depression and anxiety: The importance of subtypes and comorbidity. Cognition and Emotion, 12, 421447.

Heller, W., Nitschke, J.B., \& Lindsay, D.L. (1997). Neuropsychological correlates of arousal in self-reported emotion. Cognition and Emotion, 11, 383-402.

Heller, W., Nitschke, J.B., \& Miller, G.A. (1998). Lateralization in emotion and emotional disorders. Current Directions in Psychological Science, 7, 26-32.

Herrington, J.D., Mohanty, A., Koven, N.S., Fisher, J.E., Stewart, J.L., Banich, M.T., Webb, A.G., Miller, G.A., \& Heller, W. (2005). Emotion-modulated performance and activity in the left dorsolateral prefrontal cortex. Emotion, 5, 200-207.

Homack, S., Lee, D., \& Riccio, C.A. (2005). Test review: Delis-Kaplan Executive Functioning system. Journal of Clinical and Experimental Neuropsychology, 27, 599-609.

Isen, A.M. (1999). Positive affect. In T. Dalgleish \& M.J. Power (Eds.), Handbook of Cognition and Emotion (pp. 521-539). Chichester, England: John Wiley \& Sons.

Isen, A.M. (2001). An influence of positive affect on decision making in complex situations: Theoretical issues with practical implications. Journal of Consumer Psychology, 11, 7585 .

Jackson, D.C., Mueller, C.J., Dolski, I., Dalton, K.M., Nitschke, J.B., Urry, H.L., Rosenkranz, M.A., Ryff, C.D., Singer, B.H., \& Davidson, R.J. (2003). Now you feel it, now you don't: Frontal brain electrical asymmetry and individual differences in emotion regulation. Psychological Science, 14, 612-617.

Jones-Gotman, M. (1991). Localization of lesions by neuropsychological testing. Epilepsia, 32, S41-S52.

Jones-Gotman, M. \& Milner, B. (1977). Design fluency: The invention of nonsense drawings after focal cortical lesions. Neuropsychologia, 15, 653-674.

Keller, J., Nitschke, J.B., Bhargava, T., Deldin, P.J., Gergen, J.A., Miller, G.A., \& Heller, W. Neuropsychological differentiation of depression and anxiety. Journal of Abnormal Psychology, 109, 3-10. 
Kempler, D., Teng, E.L., Dick, M., Taussig, I.M., \& Davis, D. (1998). The effects of age, education, and ethnicity on verbal fluency. Journal of the International Neuropsychological Society, 4, 531-538.

Kenealy, P.M. (1986). The velten mood induction procedure: A methodological review. Motivation and Emotion, 10, 315-355.

Kensinger, E.A., \& Schacter, D.L. (2006). Processing emotional pictures and words: Effects of valence and arousal. Cognitive, Affective, and Behavioral Neuroscience, 6, 110-126.

Kline, J.P., Blackhart, G.C., Woodward, K.M., Williams, S.R., \& Schwartz, G.E.R. (2000). Anterior electroencephalographic asymmetry changes in elderly women in response to a pleasant and unpleasant odor. Biological Psychology, 52, 241-250.

Knight, B.G., Maines, M.L., \& Robinson, G.S. (2002). The effects of sad mood on memory in older adults: A test of the mood congruence effect. Psychology and Aging, 17, 653-661.

Kunzmann, U., Little, T. D., \& Smith, J. (2000). Is age-related stability of subjective well-being a paradox? Cross-sectional and longitudinal evidence from the Berlin Aging study. Psychology and Aging, 15, 511-526.

Laine, M. (1988). Correlates of word fluency performance. In P. Koivuselka-Sallinen \& L. Sarajarvi (Eds.), Studies in languages (Vol. 12). Joensuu, Finland: University of Joensuu.

Lee, G.P., Meador, K.J., Loring, D.W., Allison, J.D., Brown, W.S., Paul, L.K., Pillai, J.J., \& Lavin, T.B. (2004). Neural substrates of emotion as revealed by functional magnetic resonance imaging. Cognitive and Behavioral Neurology, 17, 9-17.

Lezak, M. D., Howieson, D.B., \& Loring, D.W. (2004). Executive functions and motor performance. Neuropsychological assessment (pp. 611-646). New York, NY: Oxford University Press Inc, $4^{\text {th }} \mathrm{ed}$.

Mather, M. \& Carstensen, L.L. (2005). Aging and motivated cognition: The positivity effect in attention and memory. Trends in Cognitive Sciences, 9, 496-502.

May, C.P., Hasher, L., \& Stoltzfus, E.R. (1993). Optimal time of day and the magnitude of age differences in memory. Psychological Science, 4, 326-330.

Nitschke, J.B., Heller, W., Etienne, M.A., \& Miller, G.A. (2004). Prefrontal cortex activity differentiates processes affecting memory in depression. Biological Psychology, 67, 125143.

Paulesu E., Goldacre, B., Scifo, P., Cappa, S.F., Gilardi, M.C., Castiglioni, I., Daniela, P., \& Ferruccio, F. (1997). Functional heterogeneity of left inferior frontal cortex as revealed by fMRI. Neuroreport, 8, 2011-2017. 
Perlotto, C.N. (2007). An exploration of the velten mood induction procedure in psychological symptomology. Dissertation Abstracts International: Section B: The Sciences and Engineering, 68, 2667.

Perret, E. (1974). The left frontal lobe of man and the suppression of habitual responses in veral categorical behaviour. Neuropsychologia, 12, 323-330.

Pfefferbaum, A., Adalsteinsson, E., \& Sullivan, E.V. (2005). Frontal circuitry degradation marks healthy adult aging: Evidence from diffusion tensor imaging. NeuroImage, 26, 891-899.

Phelps, E.A., Hyder, F., Blamire, A.M., \& Shulman, R.G. (1997). fMRI of the prefrontal cortex during overt verbal fluency. Neuroreport, 8, 561-565.

Phillips, L.H., Bull, R., Adams, E., \& Fraser, L. (2002). Positive mood and executive function: Evidence from stroop and fluency tasks. Emotion, 2, 12-22.

Ready, R.E. \& Robinson, M.D. (in press). Do older individuals adapt to their traits?: Personalityemotion relations among younger and older adults. Journal of Research in Personality.

Ready, R. E., Robinson, M. D., \& Weinberger, M. (2006). Age differences in the organization of emotion knowledge: Effects involving valence and time frame. Psychology and Aging, $21,726-736$.

Reuter-Lorenz, P., Jonides, J., Smith, E.S., Hartley, A., Miller, A., Marshuetz, C., \& Koeppe, R.A. (2000). Age differences in the frontal lateralization of verbal and spatial working memory revealed by PET. Journal of Cognitive Neuroscience, 12, 174-187.

Robinson, M. D., \& Barrett, L. F. (2007). Belief and feeling in self-reports of emotion: Evidence for semantic infusion based on self-esteem. Manuscript submitted for publication.

Robinson, M. D., \& Kirkeby, B. S. (2005). Happiness as belief system: Individual differences and priming in emotion judgments. Personality and Social Psychology Bulletin, 31, 1134-1144.

Robinson, M. D., Ode, S., Moeller, S. K., \& Goetz, P. W. (2007). Neuroticism and affective priming: Evidence for a neuroticism-linked negative schema. Personality and Individual Differences, 42, 1221-1231.

Robinson, M. D., \& von Hippel, W. (2006). Rose-colored priming effects: Life satisfaction and affective priming. Journal of Positive Psychology, 1, 187-197.

Ruff, R.M., Allen, C.C., Farrow, C.E., Niemann, H., \& Wylie, T. (1994). Figural fluency: Differential impairment in patients with left versus right frontal lobe lesions. Archives of Clinical Neuropsychology, 9, 41-55. 
Rusting, C.L., \& Larsen, R.J. (1997). Extraversion, neuroticism, and susceptibility of positive and negative affect: A test of two theoretical models. Personality and Individual Differences, 22, 607-612.

Schlosser, R., Hutchinson, M., Joseffer, S., Rusinek, H., Saarimaki, A., Stevenson, J., Dewey, S.L., \& Brodie, J.D. (1998). Functional magnetic resonance imaging of human brain activity in a verbal fluency task. Journal of Neurological and Neurosurgical Psychiatry, 64, 492-498.

Schmidt, L.A., (1999). Frontal brain electrical activity in shyness and sociability. Psychological Science, 19, 316-321.

Smith, S.D. \& Bulman-Fleming, M.B. (2005). An examination of the right-hemisphere hypothesis of the lateralization of emotion. Brain and Cognition, 57, 210-213.

Tamir, M., \& Robinson, M.D. (2004). Knowing good from bad: The paradox of neuroticism, negative affect, and evaluative processing. Journal of Personality and Social Psychology, 87, 913-925.

Tisserand, D.J., vanBoxtel, M.P.J., Pruessner, J.C., Hofman, P., Evans, A.C., \& Jolles, J. (2004). A voxel-based morphometric study to determine individual differences in gray matter density associated with age and cognitive change over time. Cerebral Cortex, 14, 966973.

Tomarken, A.J., Davidson, R.J., Wheeler, R.E., \& Kinney, L. (1992). Psychometric properties of resting angerior EEG asymmetry: Temporal stability and internal consistency. Psychophysiology, 29, 576-592.

Velten, E. (1968). A laboratory task for induction of mood states. Behavior Therapy and Research, 6, 473-482.

Watson, D., Clark, L.A., \& Tellegen, A. (1988). Development and validation of brief measures of positive and negative affect: The PANAS scales. Journal of Personality and Social Psychology, 54, 1063-1070.

Welsh, K.A., Breitner, J.C.S., \& Magruder-Habib, K.M. (1993). Detection of dementia in the elderly using telephone screening of cognitive status. Neuropsychiatry, Neuropsychology, and Behavioral Neurology, 6, 103-110.

Yiend, J. (2004). Cognition, emotion and psychopathology: Theoretical, empirical and clinical directions. New York, NY: Cambridge University Press. 